\title{
Templates, markers, and syntactic structure in Tashlhiyt Berber
}

\section{Mohamed Lahrouchi}

Tashlhiyt Berber presents a number of cooccurrence restrictions that prove necessary for a better understanding of word formation processes. Some of these restrictions obey morphological constraints, while others are syntactic. The examples in (1) show the morphological change between two alternative forms of nouns, traditionally called Free State and Construct State ${ }^{1}$.

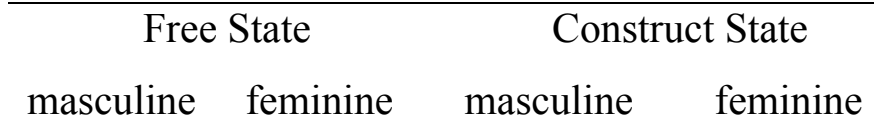

\begin{tabular}{llllll}
\hline 'boy / girl' & a-frux & t-a-frux-t & u-frux & t-frux-t & *tufruxt \\
'manure / country' & a-mazir & t-a-mazir-t & u-mazir & t-mazir-t & *tumazirt \\
'mouse' & a-srda & t-a-srda-t & u-srda & t-srda-t & *tusrdat
\end{tabular}

FS a- alternates with CS u- in the masculine forms; but with CS $\varnothing$ in the feminine forms. ${ }^{2}\{t-$ ,-t \} clearly mark feminine. From the pair afrux-tafruxt, one may assume that masculine is spelled out as Ø. From the masculine forms, one may assume that a- marks FS, u- CS. But in that case, why doesn't u- appear in the feminine CS, too ${ }^{3}$ The incompatibility of gender tand CS u- remains unclear despite several studies, including Ouhalla (1988, 1996), Guerssel (1992, 1995), El Moujahid (1997), Ennaji (2001), and Bendjaballah \& Haiden (2008), mostly couched within Generative Syntax.

Similar restrictions are found in the verbal domain. In general, the imperfective is formed either by geminating a consonant in the root or by a prefix tt-, both of which may operate jointly with vowel insertion. However, causative verbs, formed by prefixation of s- or ss-, never undergo gemination or tt- prefixation, but they all use vowel insertion to mark imperfective. The examples in (2) illustrate this phenomenon:

\footnotetext{
${ }^{1}$ The following abbreviations are used: $\mathrm{FS}=$ free state, $\mathrm{CS}=$ construct state, $\mathrm{SG}=$ singular, $\mathrm{PL}=$ plural, $\mathrm{MS}=$ masculine, $\mathrm{FM}=$ feminine, $\mathrm{NOM}=$ nominative, $\mathrm{ACC}=$ accusative.

${ }^{2}$ In Tashlhiyt Berber, any high vowel $u$ or $i$ adjacent to another vowel, typically the vowel $a$, surfaces as a glide $w$ or $j$ : e.g. ign ufrux 'the boy slept' / ifta wfrux 'the boy left'; gru 'pick up' lagraw 'assembly'; kmi 'smoke' akmmaj 'smoker'. We will not go into details about the behaviour of high vowels and the corresponding glides in Berber. The phenomenon has been thoroughly documented in Guerssel (1986) and Dell \& Elmedlaoui (2002), among others. In line with Standard analyses (see for instance Grammont 1933, Kaye \& Lowenstamm 1984, and Selkirk 1982), I will be assuming that glides and high vowels are merely phonetic reflexes of the same underlying segments. Where necessary in the analysis, $w$ and $j$ will stand for the underlying forms of the phonetic variants $[\mathrm{u}, \mathrm{w}]$ and $[\mathrm{i}, \mathrm{j}]$.

${ }^{3}$ A reviewer has kindly suggested an alternative view of the problem: assuming there is no need for a special CS marker in tfruxt, why does one appear in ufrux. Under this scenario, one would expect a CS masculine frux.
} 
(2)

\begin{tabular}{ll}
\hline Verb & Causative
\end{tabular}

\begin{tabular}{lllllll} 
& & Aorist & Imperfective & Aorist & Imperfective \\
\hline a. & 'arrive' & lkm & lkkm & ss-lkm & ss-lkam & ${ }_{\text {*ss-lkkm }}$ \\
& 'be tired' & rmi & rmmi & ss-rmi & ss-rmaj & $*_{\text {ss-rmmi }}$ \\
& 'wear' & ls & 1ssa & ss-ls & ss-lsa & $*_{\text {ss-lssa }}$ \\
b. & 'change' & badl & tt-badal & s-badl & s-badal & $*_{\text {tt-s-badal }}$ \\
& 'pick up' & mun & tt-muna & s-mun & s-muna & $*_{\text {tt-s-muna }}$ \\
& 'sit down' & gawr & tt-gawar & s-gawr & s-gawar & $*$ *tt-s-gawar
\end{tabular}

Medial gemination or tt- prefixation are thus for some reason incompatible with the causative markers ss- or s-.

The restrictions in both (1) and (2) will be shown to result from templatic constraints, handled in syntactic structures. It will be argued that gender and construct state markers compete for the same templatic position. The incompatibility of imperfective gemination or prefixation with the causative markers will be shown to follow the same kind of constraints. Basic tenets of Templatic Morphology à la Guerssel \& Lowenstamm $(1990,1996)$ and Lowenstamm (2003) will be reviewed. Of particular interest is the structure of templates, and their interaction with syntactic structure. It will be argued that templates in Tashlhiyt Berber involve only one derivational site, as opposed to the verbal template in Classical Arabic where two such sites are posited (cf. Guerssel \& Lowenstamm 1990).

The analysis is intended not only to account for the facts just presented, but also contribute a perspective on the theory on the syntax-phonology interface, where the prosodic units that constitute templates may project syntactic nodes.

The paper is organised as follows: section 1 provides some theoretical background necessary for the understanding of the proposed analysis. Section 2 presents state alternations for nouns in Tashlhiyt Berber, and reviews the more relevant previous accounts. My own analysis is provided in sections 3 to 5 . Section 6 turns to causative and imperfective formations, and then proposes an alternative analysis to the Classical Arabic verb derivation. Section 7 concludes the paper.

\section{Templates}

\subsection{Classical Arabic verb conjugation}

Templatic morphology goes back to McCarthy's seminal work $(1979,1981)$ on Classical Arabic verb conjugation, which argues for the morphological role of the skeletal tier in the derivation. It was inspired by the variety of morphological operations the verb 
undergoes in Arabic, which are not just expressed by particular affixes, but also by quantity alternations within root material, the hallmark of Semitic languages. Well before, linguists of the Middle Ages such as Sibawayh used faSal 'do' as model for derivation. The novelty with McCarthy is the way he extends the proposal of autosegmental phonology to Classical Arabic verbal conjugation, showing that the various forms of the verb are obtained in a natural way from the association of a consonantal root with vocalic melodies and affixes to prosodic templates. These templates, which may consist of any string of $\mathrm{C}$ and $\mathrm{V}$ positions ordered in a fixed way, are viewed as fully-fledged morphemes designed to convey specific grammatical information. For instance, the forms kataba 'he wrote', kattaba 'he made write', and ka:taba 'he corresponded' are derived from the association of the triconsonantal root $k t b$ and the vowel melody $a$ to the templates CVCVCV, CVCCVCV and CVVCVCV, respectively. The same material associated with the prefix $m$ - to the template $\mathrm{CV}-\mathrm{CCVC}$ lead to the form maktab 'office', opposed to maktu:b 'written' whose vowel melody and template are slightly different.

In order to reduce the number of templates proposed by McCarthy (1979: 135, and 1981: 386), Guerssel \& Lowenstamm (1990) and Lowenstamm (2003) suggest that the verbal forms in Classical Arabic are derived by means of a single template of the form in $(3)^{4}$ :

$$
\mathbf{C} \mathbf{V}-\begin{array}{llllllllllllllllll}
\mathrm{C} & \mathrm{V} & \mathbf{C} & \mathbf{V} & \mathrm{C} & \mathrm{V} & \mathrm{C} & \mathrm{V} \\
\hline
\end{array}
$$

Two observations are in order. First, the template consists of alternating $\mathrm{C}$ and $\mathrm{V}$ positions. The reader is referred to section 1.2 and references therein for an outline of this approach to syllable structure. Second, the syllables in bold are derivational head positions. The boxed syllables constitute the complement of the head. The identification of one of the head positions by some affix or root material derives one verbal form. For example, given the triconsonantal root qsm "divide", if the medial derivational position is filled by means of Cspreading, the resulting verb will be qassama 'he subdivided, he classified' (see 4a); the same position identified by means of V-spreading leads to the verb qa:sama 'he shared'(see 4b).

(4) a.

\footnotetext{
${ }^{4}$ The template proposed by Lowenstamm (2003) has a slightly different shape: the prefixal CV- has been omitted since only verbal forms involving medial gemination (form II kattaba) or vowel lengthening (form III $k a: t a b a$ ) have been discussed.
}

b. 


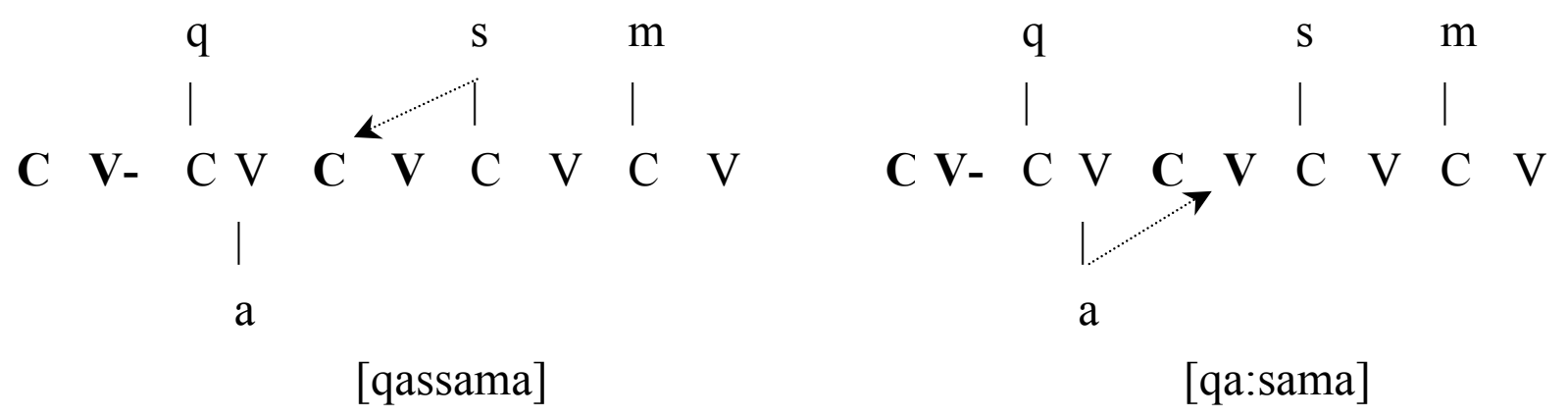

If the prefixal position is identified by the prefix $n$-, the resulting verb nqasama 'it divided' has a reflexive meaning. If neither of prefixal or internal sites is identified, the output is qasama 'he divided', which stands for the basic form of the verb, also called Form I in standard analyses. Both forms are represented below in (5):

(5)

a.

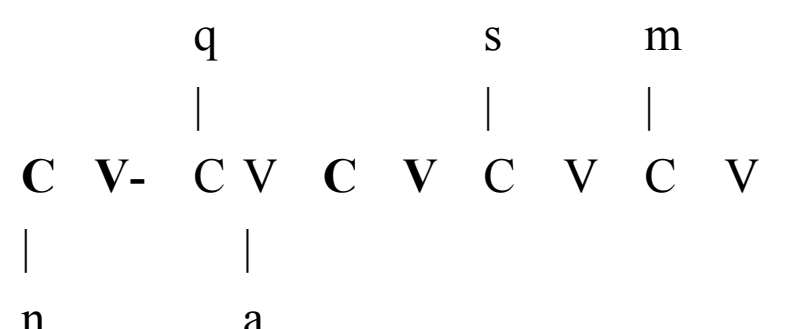

[nqasama] b.

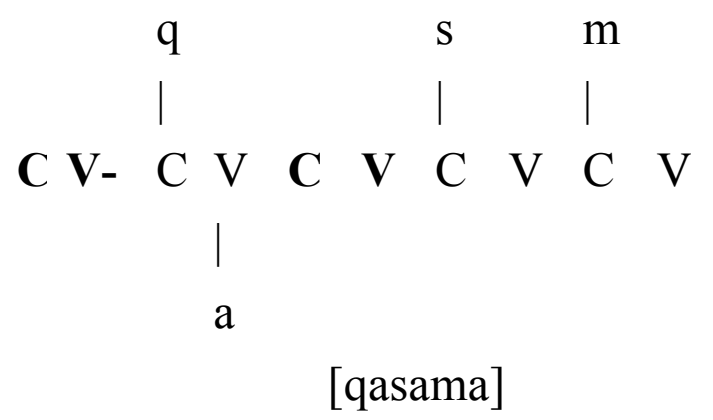

The careful reader will have noticed that in none of the forms represented in (4) and (5), both derivational positions are identified at the same time. Accordingly, Guerssel \& Lowenstamm assume that only one head position is identified in each form. The identification of both heads leads to undesirable double-headed forms, the authors argue. Their argument is illustrated by the intensive form of reflexive nkasara 'it broke': although semantically viable, the form *nkassara 'it shattered' is ruled out since both head positions are identified by means of $n$ prefixation and medial consonant gemination. This is shown below in (6). The same situation is found in *nqassama.

(6) *nkassara 'it shattered'

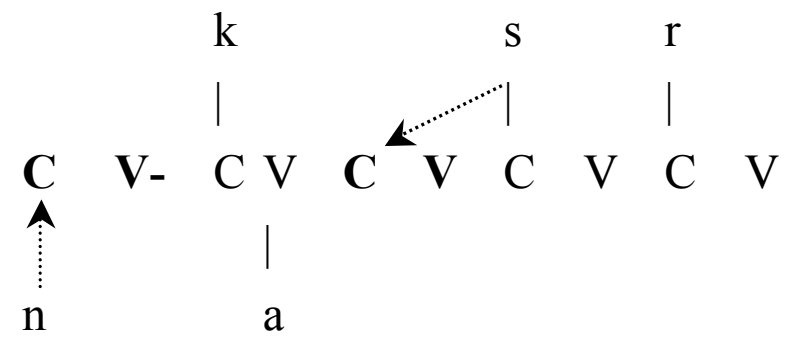


The argument is apparently tenable for reflexive $n$ - which never co-occurs with medial gemination (*nkassara) or vowel lengthening (*nka:sara). However, other derivational prefixes easily combine with these two formatives. The verb taqa:sama 'he shared' is one example in this respect: Guerssel \& Lowenstamm's analysis does not explain why the prefix $t$ - co-occurs with vowel lengthening, given that the first would connect to the prefixal CVwhile the long vowel would spread into the medial CV. The same situation occurs taSallama 'he learned', derived from the root Slm 'know'. This form should have been ruled out, according to the above analysis.

The templatic hypothesis will be used thereafter in the analysis of state alternations, and causative and imperfective formations in Tashlhiyt Berber (sections 5 and 6). One thing should be clarified though. In Tashlhiyt Berber, templates may contain as many CV units as necessary to accommodate both the root and the affixal material, in contradistinction with Classical Arabic in which a unique template, with a fixed number of CV units, is posited for verbs. The number and the size of templates will make little difference in the case of Tashlhiyt Berber. Rather, focus will be on their structure: It will argued that only one derivational $\mathrm{CV}$ is needed in order to account for the relevant data.

\subsection{CVCV model}

As an offspring of Government Phonology (Kaye et al. 1990), the CVCV model holds that the syllable structure universally reduce to a strict alternation of non-branching onsets and non-branching nuclei, viz. $\mathrm{C}$ and $\mathrm{V}$ positions, which interact laterally to derive different surface syllable types. Only consonantal segments are linked to $\mathrm{C}$ positions and only vocalic segments appear in V positions. The reader is referred to Kaye \& Lowenstamm (1991) for a justification of this view of the syllable structure of Arabic. Moreover, within this model, the familiar configurations known as a light open syllable, a closed syllable, a long vowel and a geminate share exactly the same skeletal material: CVCV.

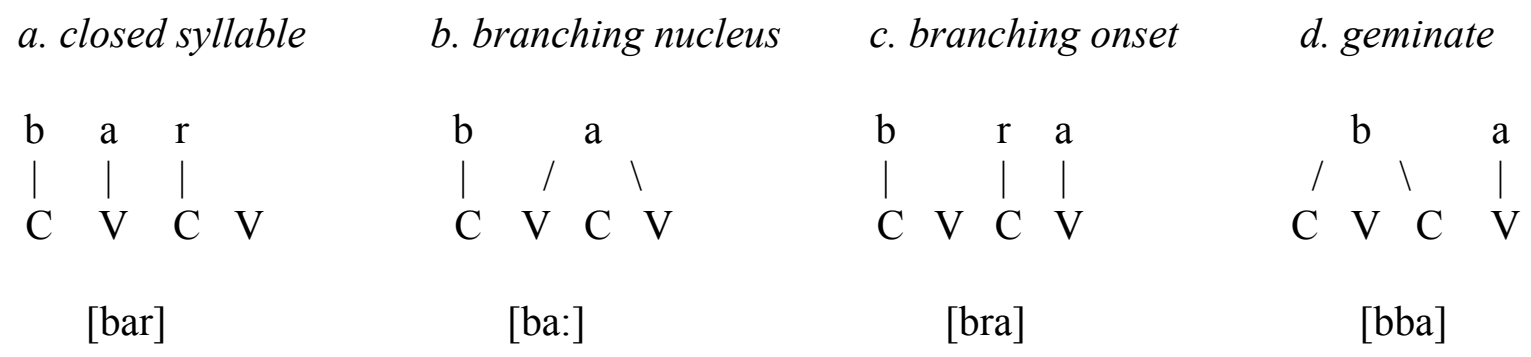


As can be seen from these representations, there are no rhymes, no codas and no branching constituents. The differences in the surface syllabic structures lie in the way segments are associated to the skeletal tier:

a. The consonant located in the coda of the surface closed syllable in (7a) appears in the onset of the second syllable whose nucleus is empty.

b. The long vowel in (7b) contains an empty $\mathrm{C}$ position whereas the geminate in (7d) has an empty $\mathrm{V}$ position between its members.

c. The branching onset in (7c) has an empty $\mathrm{V}$ between its consonants.

Skeletal positions that have no phonetic realisation are said to be licensed to remain empty by virtue of the government relation that they share with the neighbouring segments. Proper Government is one such relation which allows a $\mathrm{V}$ position to remain empty when followed by a vowel. This proves particularly interesting in explaining the well-known $\mathrm{V} / \varnothing$ alternation found in many languages such as in Moroccan Arabic ktab 'he wrote' where the V position between $/ \mathrm{k} /$ and $/ \mathrm{t} /$, properly governed by the schwa that appears between $/ \mathrm{t} /$ and $/ \mathrm{b} /$, remains empty, opposed to katbu 'they wrote' where the same position, non-governed, surfaces as schwa. The same phenomenon occurs in certain Berber varieties such as Kabyle: for example, the vocalic position between $/ \mathrm{x} /$ and /d/ remains empty in $x ð \partial m$ 'work!' but not in хәðтәь 'I worked'. Interestingly, this position is properly governed by the following schwa in the first form but not in the second one (see Bendjaballah 2001: 188). This is illustrated below in (8):

a.

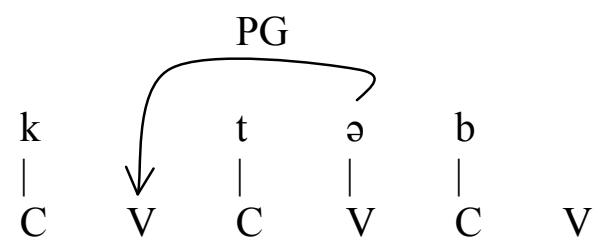

b. $\quad k a t b u$ 'they wrote'

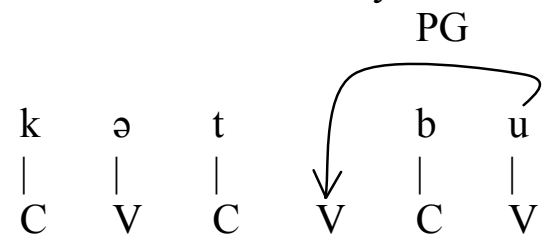

Kabyle Berber

c. $\quad x ð a m$ 'work!'

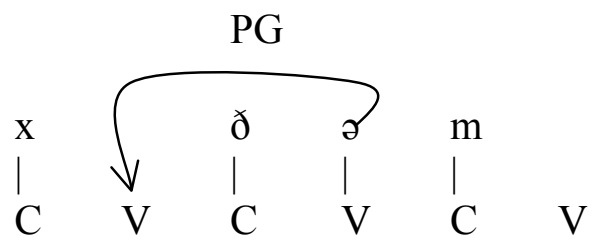

d. $\quad$ хəðтәь 'I worked'

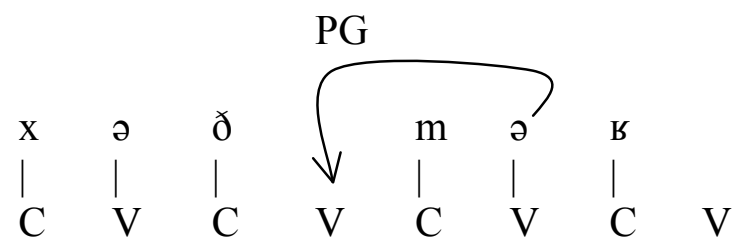

Likewise, in French schwa can be omitted only when followed by a vowel: For example, in am[a]ner 'bring', the schwa between $/ \mathrm{m} /$ and $/ \mathrm{n} /$ may not be pronounced since properly governed by the following vowel. 
In Berber varieties where schwa does not occur, syllabic consonants arise. Any vocalic position lacking proper government systematically hosts one syllabic consonant (see Hammane 2010, and Blaho 2004 and Scheer 2008 on Slavic). To illustrate this, let us consider the verb $x d \partial m$ 'work!' just discussed in Kabyle Berber. In Tashlhiyt, no vowel shows in the surface form of this verb. Accordingly, the consonant $/ \mathrm{m} /$, the most sonorous in the string, fills the $\mathrm{V}$ position to its left, and then governs the empty $\mathrm{V}$ between $/ \mathrm{x} /$ and $/ \mathrm{d} /$.

For more details about the CVCV model, the reader is referred to Lowenstamm (1996) and Scheer (2004). Many recent works endorse this approach to syllable structure, including Bendjaballah (2001, 2003, and 2007), Scheer (1998, 2008, and 2011), Ségéral \& Scheer (2001 and 2008), Barillot (2002), Aïm (2003), Rucart (2006a, and 2006b), Kula (2008), Lahrouchi (2003, and 2008), and Lahrouchi \& Ségéral (2009, and 2010).

\subsection{Berber Template morphology}

The templatic character of the morphology of Berber ${ }^{5}$ is not as well established as it is in Semitic, in spite of important studies (see Guerssel 1992, Idrissi 2000, Bendjaballah 2001, Bensoukas 2001, Lahrouchi 2003, 2008, and Lahrouchi \& Ségéral 2010 among others) showing that various phenomena such as causatives, reciprocals, passives, imperfective, internal plurals, negative preterit, and language games are better analysed in terms of templatic processes. Some of these phenomena suggest the existence in Berber of fixed-shape templates, over which specific morphological operations are realized. The imperfective formation, involving the gemination of one consonant in the root (e.g. lkm / lkkm 'arrive'), is a good example in this respect (see Lahrouchi 2008). Other phenomena call for an interface approach, in which templates are viewed as internally structured objects whose prosodic units may project syntactic nodes. This approach will be investigated in the analysis of the facts of interest here.

Owing to their non-concatenative style of morphology, Afroasiatic languages, and more particularly Semitic and Berber, probably embrace more than any other language the hypothesis that templates convey specific grammatical information, and that their prosodic units may project syntactic nodes. In subsequent sections, I will demonstrate that the solution to the incompatibility of gender $\mathrm{t}$ - with $\mathrm{CS} \mathrm{u}$-, and imperfective gemination or tt- prefixation with the causative marker results in the way templatic positions are involved in syntactic

\footnotetext{
${ }^{5}$ Berber is an Afroasiatic language spoken in large parts of North Africa, mainly in Morocco and Algeria, to a lesser extent in Mali, Niger, Libya, Egypt, Tunisia and Burkina Faso. Three main varieties are found in Morocco : Tashlhiyt, the variety investigated here, is spoken in southern Morocco; Tamazight is spoken in the Middle Atlas, and Tarifit is spoken in northern Morocco. Kabyle is the main variety spoken Algeria. Tamashek or Touareg is found in Niger, Mali and southern Algeria (see Chaker 1992).
} 
structures. This is a non-trivial solution, which might appear to steer against the prevailing analyses, generally agreeing on the fact that competition does not necessarily hold within syntactic structures, and that there is no reason for some syntactic category to take precedence over other categories. It will be shown here that templatic constraints may explain the covert realization of some morphosyntactic categories in certain contexts.

Before turning to the analysis of the cooccurrence restrictions that CS and gender markers undergo, let us examine their distribution, and review some recent accounts.

\section{State and Gender alternations}

In Tashlhiyt Berber, nouns are inflected for gender, number, and state. The examples in (9) illustrate these declensions:

\begin{tabular}{|c|c|c|c|c|c|c|c|c|}
\hline & \multicolumn{2}{|c|}{ MS } & \multicolumn{2}{|c|}{ FM } & \multicolumn{2}{|c|}{ MS } & \multicolumn{2}{|c|}{ FM } \\
\hline & SG & PL & SG & PL & SG & PL & SG & PL \\
\hline 'boy / girl' & afrux & ifrxan & tafruxt & tifrxin & ufrux & ifrxan & tfruxt & tfrxin \\
\hline 'manure/country' & amazir & imazirn & tamazirt & timizar & umazir & imazirn & tmazirt & tmizar \\
\hline 'ox / cow' & afunas & ifunasn & tafunast & tifunasin & ufunas & ifunasn & tfunast & tfunasin \\
\hline 'pigeon' & atbir & itbirn & tatbirt & titbirin & utbir & itbirn & ttbirt & ttbirin \\
\hline 'fishing rod' & аваlim & ікаlimn & tаваlimt & tisalimin & иваlim & іваlimn & tsalimt & tваlimin \\
\hline 'mouse' & abrda & isrdajn & tasrdat & tisrdajin & ubrda & isrdajn & turdat & tørdajin \\
\hline
\end{tabular}

The consonant / $/$ prefixed and suffixed to the stem marks the feminine in the singular forms; in the plural, however, only the prefix t- occurs. Number is conveyed by means of vowel alternation: SG a- alternates with PL i-, most often coupled with -n suffixation ${ }^{6}$. In certain cases, the suffix $-n$ is replaced by vowel alternation internal to the stem (e.g. asaru (SG) / isura (PL) 'pipe'). Other nouns show a stable initial vowel which remains unchanged in SG and PL, FS and CS, referring to the so-called thematic vowel (e.g. FS adgal (SG), adgaln (PL) / CS wadgal (SG), wadgaln (PL) 'widower', cf. Dell \& Jebbour 1991). Table (10)

\footnotetext{
${ }^{6}$ One anonymous reviewer rightly noticed that the feminine suffix $-\mathrm{t}$ is incompatible with the plural suffix $-\mathrm{n}$ : for example, singular tafruxt 'girl' alternates with plural tifrxin and not *tifrxtin. If this is handled templatically, it might constitute, according to the reviewer, a challenge to the view of syntax as the cause of preference of certain grammatical markers over others, because gender is lower in the structure than number. -t should therefore take precedence over $-\mathrm{n}$, and not the reverse. This interpretation, if correct, would necessarily impact our analysis of the incompatibility of gender $t$ - with construct state $u$-. I believe instead that the prefix $t$ - is the only feminine marker in Tashlhiyt Berber. The suffixed counterpart, which occurs in singular forms, is merely epenthetic, filling a tempaltic position that would otherwise remain empty. This is evidenced by the fact that many singular forms use only the prefix t- to mark the feminine (e.g. tili 'sheep', $\operatorname{targ}^{w} a$ 'watercourse', tasa 'liver', tansa 'burrow', tasga 'side'), while none use only the suffix -t. When plural $-\mathrm{n}$ is added, -t epenthesis no longer occurs.
} 
summarizes these distribution of prefixes, which proves necessary to understanding the analysis we will be developing in this paper:

\begin{tabular}{|l|l|l|l|l|}
\cline { 2 - 5 } \multicolumn{1}{c|}{} & \multicolumn{2}{c|}{ FS } & \multicolumn{2}{c|}{ CS } \\
\cline { 2 - 5 } \multicolumn{1}{c|}{} & MS & FM & MS & FM \\
\hline SG & a- & ta- & u- & t- \\
PL & i- & ti- & i- & t- \\
\hline
\end{tabular}

The following question arises in light of these facts: Why does the CS marker u- never occur with the FM marker t-? For instance, why do we get CS tfruxt and not *tufruxt? Before answering this question it is important to list the contexts in which FS and CS occur.

State alternations in Tashlhiyt Berber reflect the position of the NP in the syntactic structure. In VSO clauses, subject NPs directly following the verb appear in the CS form, while in SVO order they show a FS form (compare below 11a to 11b). Object NPs are in the FS form in both orders, although one of these (11c) involves direct adjacency between the verb and the NP. In passive sentences, the subject always appears in the CS form (11d).

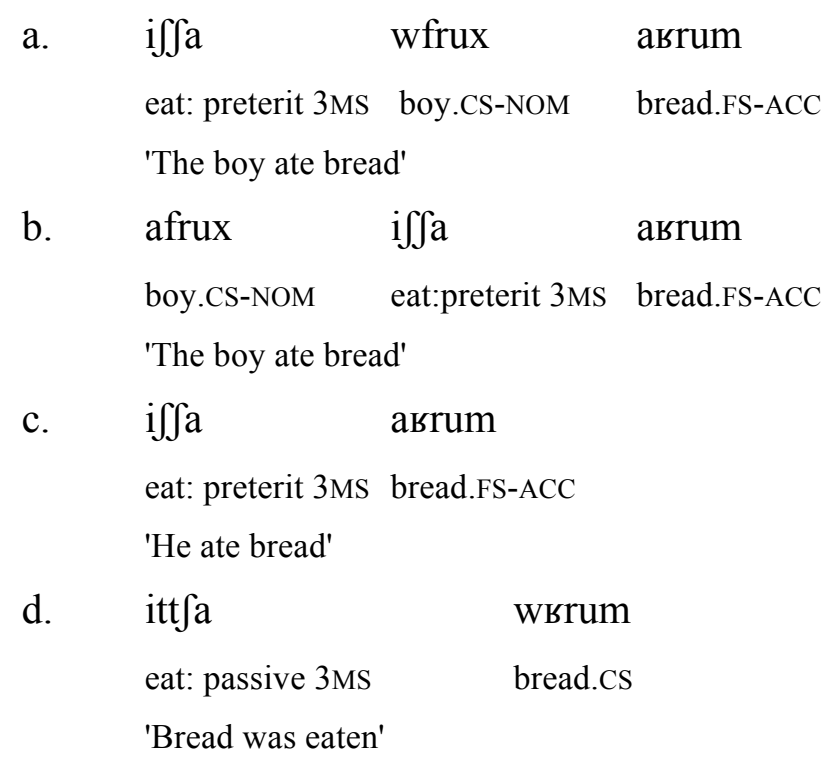

NP complements of light prepositions such as $s$ 'with, by', $d$ 'and' and $b$ 'in' appear in the CS form. So do the complements of quantifiers like jan 'one' and sin 'two'. The examples in (12) illustrate these situations:

a. arrum $\quad / \mathrm{n} \quad$ ufrux $/ \rightarrow$ [uufrux $]$ 


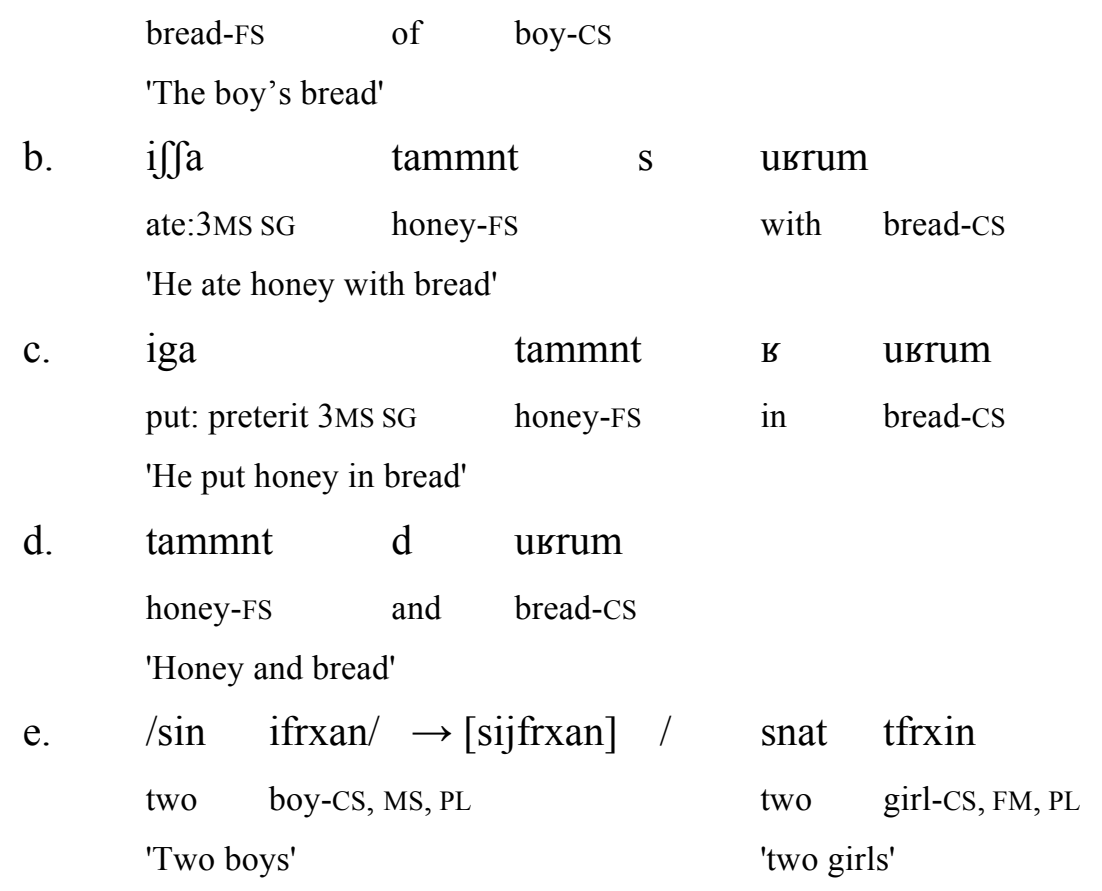

However, not all prepositions call for CS; NP complements of heavy prepositions ${ }^{7}$ exhibit the FS form, as shown in the examples in (13) (see also Bendjaballah \& Haiden 2008):
a. $\quad$ i $\int \mathrm{a}$
eat: preterit $3 \mathrm{MS} \mathrm{SG}$
tijmi
bla abrum
(* bla usrum)
b. ifta
sauce-FS without bread-FS
go: preterit $3 \mathrm{MS} \mathrm{SG}$
wfrux ar adrar
(*ar udrar)
boy-CS as far as mountain- FS

Further examples on the distribution of CS and FS in Tashlhiyt Berber are found in El Moujahid (1997: 114). Let us now survey some accounts of these alternations.

\section{A Portmanteau morpheme}

Much work has been devoted to state alternations in Berber, mostly developed within the generative framework (see Achab 2003; Bader \& Kenstowicz 1987; Bendjaballah \& Haiden 2008; Dell \& Jebbour 1991; El Moujahid 1997; Ennaji 2001; Guerssel 1992, 1995; Ouhalla 1988, 1996, among others). The common denominator of these studies is that state alternations relate to definiteness and case. Indeed, the initial vowel of the noun is viewed as a determiner in a DP projection. Ouhalla (1988) and Guerssel $(1987,1992)$ further assign this vowel a role in the realization of KP. According to Guerssel (1992: 175):

\footnotetext{
${ }^{7}$ The dichotomy light vs. heavy refers to phonological weight, as stated in Bendjaballah \& Haiden (2005: 2): "light means one segment". Prepositions containing more than one segment are seen as heavy. This weight distinction apparently correlates with the distribution of state. However, while it is true that all light prepositions call for CS, not all heavy prepositions have their complement in the FS form. For instance:

ifta dar urgaz (not *dar argaz).

go: preterit 3MS SG at man-CS

'He went to the man'
} 
"[...] the concept of State has no validity as a theoretical notion, $[\ldots]$ what

has been labeled a Construct State form is either a Determiner Phrase, or a

Kase Phrase where the head K is not realized".

However, a notable structural difference is posited: in the FS initial a- is analysed as a kind of "portmanteau" morpheme (cf. Guerssel 1992: 187) that merges two functional heads D and K, while in the CS initial w- stands for D. The forms azru 'rock-FS', $s$ wzru 'with the rock', wzru 'rock-CS', and $d y$ tsrit ' in the mill', from Guressel (1992: 117, 194), are represented in (14):

a.

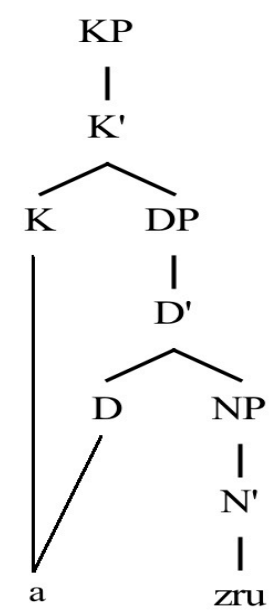

b.

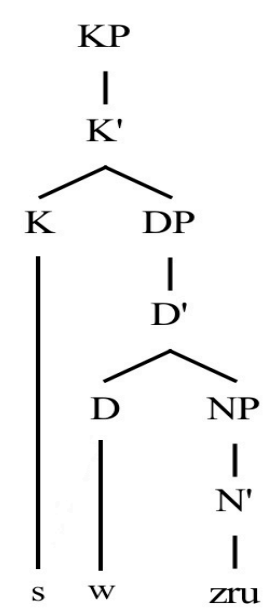

c.

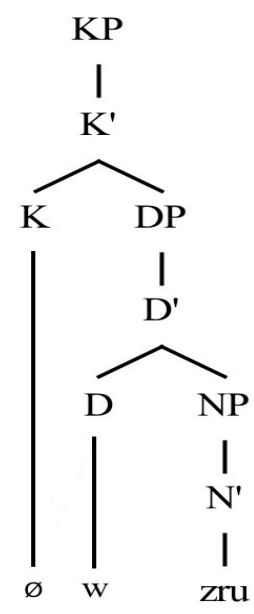

d.

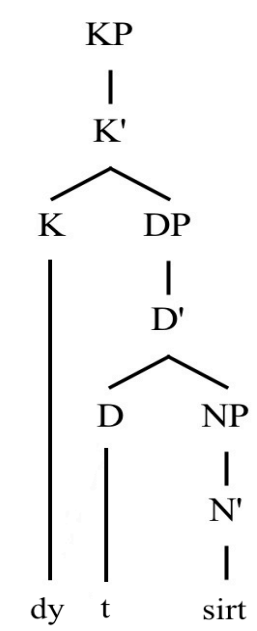

In (14a), the initial vowel a- is dominated by K and D. In (14b), w- is a determiner and the light preposition $s$ fills the $\mathrm{K}$ head as a case marker. In $(14 \mathrm{c})$, w- is attached to D while $\mathrm{K}$ remains empty. In (14d), the feminine marker t- stands for Determiner, and $d y$ appears under K. From Guerssel's perspective, light prepositions play a central role in the morphological realization of $\mathrm{K}$ : their absence leads to an empty $\mathrm{K}$ position (see $14 \mathrm{c}$ ).

An alternative to Guerssel's analysis is provided in Bendjaballah \& Haiden (2008). Examining similar prepositional phrases in Kabyle Berber, a variety spoken in North-eastern Algeria, the authors combine morphosyntactic and templatic analyses, arguing for a prosodic deficiency in the CS. According to them, both FS and CS have the same template, composed of a fixed number of CV units, the first two of which host grammatical markers. Prosodic deficiency in the CS arises from the fact that one CV unit in the template remains empty, whereas in the FS the whole template is filled. To illustrate this, consider the FS form axxam 'house' and its corresponding CS waxxam, represented below in (15): 
a.<smiles>[AlH2]C[AlH2]</smiles>

$\mathrm{a}$
FS: axxam 'house'

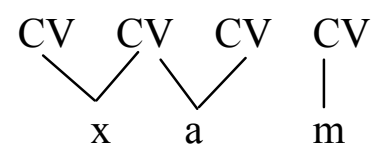

b.

CS: wəxxam

Taking up the hypothesis first developed by Lowenstamm (1991), according to which peripheral vowels in Ethio-Semitic and Moroccan Arabic are phonologically long 8 , Bendjaballah \& Haiden (2008: 36) suggest that in the FS axxam (15a), a- identifies the first two CV units in the template, whereas in the CS waxxam (15b), w- connects only to one CV unit, leaving the outer (initial) CV empty, hence resulting in a prosodic deficiency.

The same situation obtains in the corresponding feminine forms $\theta$ axxam $\theta$ 'room' and

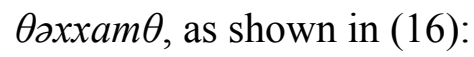

a.<smiles>[CH]C([Hg])[Hg]</smiles>

FS: $\theta \operatorname{axxam} \theta$ 'room'

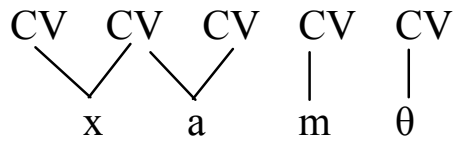

b. CS: $\theta ə x x a m \theta$

The gender marker $\theta$ - connects to the outer (first) CV unit in the FS form $\operatorname{\theta axxam} \theta$ (16a), but to the inner (second) CV unit in the CS form Oaxxam $\theta$ (16b). Therefore, in (15) and (16), parallel is drawn between $\mathrm{w}$ - and $\theta$ - which connect to only one skeletal position, and a- which attaches to two positions.

Within prepositional phrases, the outer CV unit in the CS waxxam and $\theta$ axxam $\theta$ hosts light prepositions, which are assumed to be floating markers. The situation is illustrated in (17) with the form gOxxxamt 'in the room':

\footnotetext{
${ }^{8}$ The dialects of the Maghreb are usually said to have lost the short vowels of Classical Arabic, whereas the long vowels become short. Plenty of examples support this hypothesis: for instance, Classical Arabic kataba 'he wrote', kita:b 'book', labisa 'he dressed', muSallim 'teacher, master', and ћima:r 'donkey' surface as ktab, ktab, lbəs, $m$ Səllam, and $\hbar m a r$ in Moroccan Arabic. Schwas appear where necessary to avoid complex consonant clusters. Based on theses facts, especially that the remaining peripheral vowels in the dialects of the Maghreb correspond exactly to Classical Arabic long vowels, Lowenstamm (1991: 959) suggests that peripheral vowels in these dialects "never ceased to be long" and that they still need "to be associated associated with branhing nuclei" (p. 960). Later, the proposal has been extended to Berber languages in contact with the Arabic dialects of the Maghreb (see Bendjaballah 1999, 2001, 2005; Idrissi 2000; and Lahrouchi \& Ségéral 2010, among others).
} 
(17) gOxxxamt 'in the room'

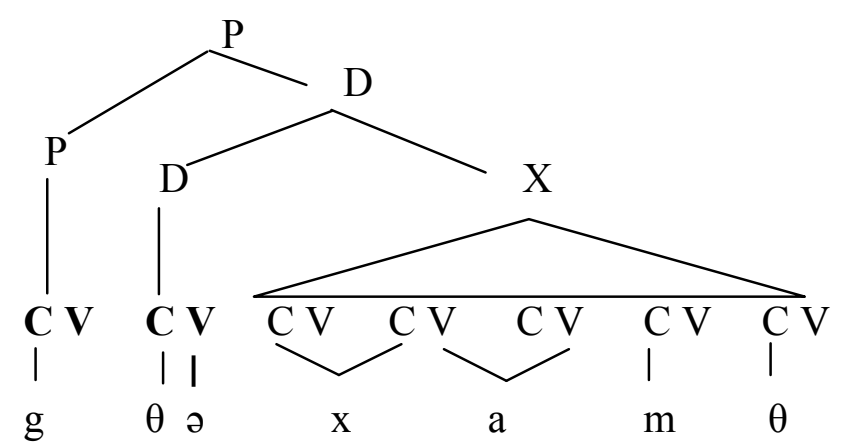

The crucial point within Bendjaballah \& Haiden's analysis is that two templatic sites occur at the left periphery of the noun in Kabyle Berber. In the FS, both sites are identified, whereas in the CS only the inner site is identified. The outer one either remains empty or hosts light prepositions. In Tashlhiyt Berber, it will be argued that an initial templatic site is responsible for the incompatibility of the CS marker w- with the gender prefix t-, and that of the causative marker s- with the imperfective prefix $\mathrm{tt}$-.

Before expounding the analysis, we must review the syntactic structure of the noun in Berber. In the analyses discussed above (see also Ouhalla 1988, and Achab 2003), the NP is presented as part of a maximal projection the DP, headed by a- in the FS and w- in the $\mathrm{CS}^{9}$. This assumption remains questionable for reasons to be discussed in the following section.

\section{Where is $D$ ?}

The controversy surrounding definiteness in Berber relates to the widespread assumption that noun phrases are universally headed by determiners in conformity with the DP hypothesis of Abney (1987). Paralleling well-established analyses in other languages such as Arabic, English and French, several works including Ouhalla (1988), Guerssel (1987, 1992), Ennaji (2001), Achab (2003), and Bendjaballah \& Haiden (2008) argue that the initial vowel in nouns functions as a determiner (see also Basset 1932 and Vycichl 1957). Among the arguments put forth are those related to gender and number realization: the initial vowel in nouns bears gender and number marking just as determiners do in French. For instance, MS SG afrux alternates with FM SG tafruxt, and MS PL ifrxan alternates with FM PL tifrxin, comparable to French definite articles $l[a] / l[a] / l[e]$ "the - SG MS / SG FM / PL", whose vowels show a regular alternation. Other arguments include case marking: as noted in section

\footnotetext{
${ }^{9}$ The DP hypothesis is also assumed in Ennaji (2001), though it is used in a quite different manner, focusing on genitive constructions where CS nouns are DPs headed by D.
} 
3, Guerssel $(1987,1992)$ analyses the initial vowel a- as a default case marker heading KaseP, which selects a DP headed by gender markers t- and w-.

Alternative analyses to DP hypothesis mainly discuss definiteness in NPs and the behaviour of the alleged determiner. Such analyses argue that definiteness is far from established in Berber. Indeed, NPs might have definite or indefinite readings depending on the context in which they occur. According to Ouhalla (2005: 661) "there are good reasons to conclude that pre-stem inflection no longer corresponds to definite articles in modern Berber. Berber is routinely described as a language without definite articles, where the (in)definiteness of noun phrases is determined by discourse considerations."

Boukhris et al (2008: 61) further argue that:

"A la différence d'autres langues ayant un article défini représenté par un morphème distinct (arabe: al, français: le/la, les, anglais: the, etc.), l'amazighe n'a pas développé un tel morphème. La définitude du GN n'est pas associée à la fonction de la voyelle initiale prise souvent pour l'article défini en amazighe. En effet, un nom à initiale vocalique peut être indéfini en se combinant au morphème d'indéfinitude qui a la même forme que le numéral jan/ jin / jnn 'un' et sa variante au féminin jat / jit / jft 'one-FM' [...] La définitude du GN se réalise alors par d'autres procédés, parmi lesquels le sémantisme du substantif (noms propres, noms de lieu, noms de parenté, etc.) et les expansions du nom (possessif, complément de nom, nom de qualité, participe qualifiant, proposition relative)."

[Contrary to other languages that have a distinct definite article (Arabic: $a l$, French: le/la, les, English: the), Amazighe [Berber] has no such morpheme. NP definiteness is not related to the function of the initial vowel, often considered as a definite article in Amazighe. Indeed, a vowel-initial noun can be indefinite when combined with an indefinite morpheme such as the numeral jan/jin/jnn 'one' and its feminine counterpart jat/jit/ js $t$ 'one$\mathrm{FM}^{\prime}[\ldots]$ NP definiteness is then realized by means of other processes, including semantics of the noun (proper names, place names, names of relatives, etc.) and its expansions (possessive, noun complement, quality noun, qualifying participles, relative clause).]

Further arguments that may be raised against the DP analysis relate to the cooccurrence restrictions that determiners undergo in certain languages, but not in Berber. For instance in English, demonstratives, quantifiers and possessives do not occur with (in)definite articles : e.g. *this the boy / *this a boy, *one the boy / *one a boy, *my the book. The same is true for French definite articles: e.g. *ce le garçon 'this the boy', *plusieurs les garçons 'many the boys', *mon le livre 'my the book'; while Italian il mio libro is just fine. The situation in Classical Arabic is quite similar to that of English and French. Quantifiers and possessives do not occur with the definite article al-: e.g. *tala:tatu al-awla:di / tala:tatu awla:din "three 
boys", *al-kita:bi: "my the book" / kita:bi: "my book". No such restrictions are found in Berber. The initial vowel in nouns may occur with demonstratives, quantifiers and $\operatorname{possessives}^{10}$ :

a. afrux-ad

boy-FS-this

'This boy'

b. /jan ufrux/ $\rightarrow$ [jawfrux]

one boy-CS

'One boy'

c. afus-inu

hand-FS-my

'My hand'

The answer to the question of definiteness in Berber must therefore reside elsewhere, and not within the morphological shape of nouns. Indeed, following Chierchia (1998), Achab (2003: 17) explored the possibility that both CS and FS nouns have a covert definite operator OP dominating DP. Its presence or absence determines the definite or indefinite reading of the nouns.

In sum, the issue of definiteness in Berber remains under debate, and views differ as to the way the initial vowel should be analysed. For the time being, we will focus on the templatic facet of the problem. We will return to the morphosyntactic structure of nouns later, and an attempt will be made to implement the templatic analysis using a syntactic structure.

\section{Gender and Construct State}

\subsection{The templatic effect}

Template morphology offers an interesting descriptive potential, some aspects of which meet with the facts discussed above. One crucial tenet of template theory is the existence of empty templatic sites which host specific morphological material. The initial CV in the template (3) is one such $\operatorname{site}^{11}$, which allows one to capture the cooccurrence restrictions under discussion in Tashlhiyt Berber.

\footnotetext{
${ }^{10}$ Some languages present exceptions to the generalizations mentioned in the case of English, French and Classical Arabic, but never all of them, except Berber. For instance, Hungarian and Galela are reported to allow using (in)definite articles with demonstratives Rijkhoff (2002 : 179). Italian is also one example that allows using definite articles with possessives, e.g. il mio libro 'the my book' (see above in the text).

${ }^{11}$ Lowenstamm (1999) is an attempt to generalise the proposal to languages other than Semitic. Specifically, it is argued that each major category has an empty initial $\mathrm{CV}$, where cliticization takes place.
} 
As noted in the examples in (9) and (11), CS w- never cooccurs with gender t-: FS afrux alternates with CS ufrux 'boy', while FS tafruxt contrasts with CS tfruxt 'girl', and not *tufruxt as would be expected phonologically. These facts suggest that gender t- and CS wcompete for the same position in the template, namely the consonantal position in the initial CV site. The forms represented in (19) illustrate the proposal:

a. MS CS: $w$ frux $>[$ ufrux $]$

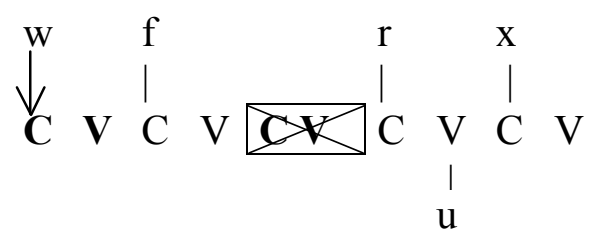

$c$.

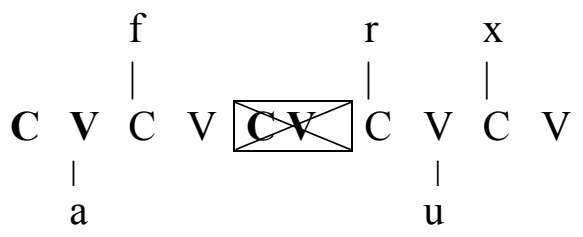

$b$. FM FS: $t$ fruxt

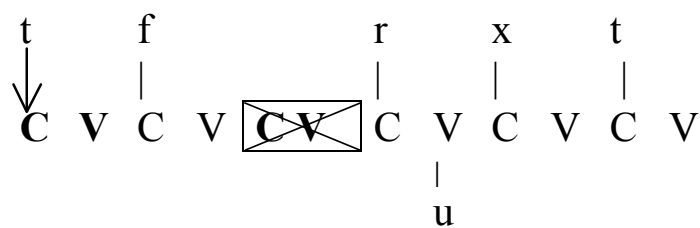
FM FS: tafruxt

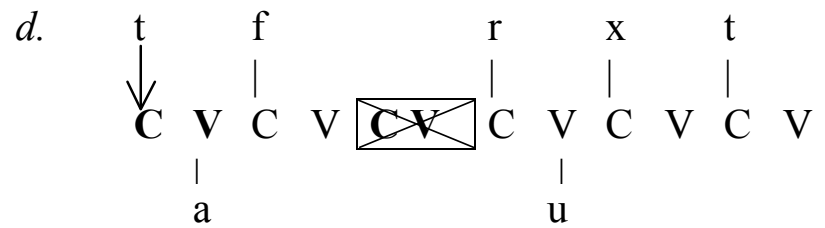

Only one empty $\mathrm{C}$ slot is available in the initial position of the template (the $\mathrm{CV}$ in question is bolded). It is assumed that gender t- connects to this empty $\mathrm{C}$ slot before CS w- is added. In other words, gender takes precedence over CS, yielding a feminine form from which CS w- is absent. However, in the masculine forms, where gender is unmarked, CS wshows up. In the FS forms, no such alternation is found, since gender t- and the initial vowel a- connect to $\mathrm{C}$ and $\mathrm{V}$ positions.

In addition, the careful reader will have noticed that the templates in (19) differ from the one proposed by Guerssel \& Lowenstamm in the case of Classical Arabic, given in (3): Firstly, the above templates are nominal, whereas the template in (3) is verbal. Secondly, the template in Classical Arabic has a fixed shape (5 CV units), while the templates in (19) vary from masculine to feminine and form singular to plural, in order to accommodate the additional affix material. However, both in both languages, the templates show two derivational CV positions, one of which remains empty in line with the hypothesis put forth in the case of Classical Arabic (see section 1.1). According to this hypothesis, which we are assuming so far in the analysis, both $\mathrm{CV}$ positions cannot be identified in the same form. 
Hence, the crossed CV's in the forms in (19). Later, in section 6 an argument will be made that only one derivational $\mathrm{CV}$ is needed in each template.

Finally, it should be noticed that the vowels in Tashlhiyt Berber are attached to only one skeletal position, contrary to what Benjaballah \& Haiden (2008) claimed in the case of Kabyle Berber (see section 3 above). The hypothesis that peripheral vowels connect to two skeletal positions, crucial in the analysis proposed by Benjaballah \& Haiden (2008), does not affect the analysis advocated here: Whether the vowels attach to one V position or whether they branch, the output remains the same. In the remainder of this paper, the vowels will uniformly be associated to only one $\mathrm{V}$ position.

In the next section, I will attempt to implement the templatic analysis just presented to a syntactic structure.

\section{$5.2 n P, D P$}

Assuming the DP hypothesis and a head movement approach, the competition between gender $\mathrm{t}$ - and determiner $\mathrm{w}$ - derives as shown (20), where $\mathrm{n}$ is the locus of Gender (see Lowenstamm 2008: 112 on this issue) $)^{12}$ :
a. FM CS: tfruxt
b. MS CS: $w f r u x>[$ ufrux]

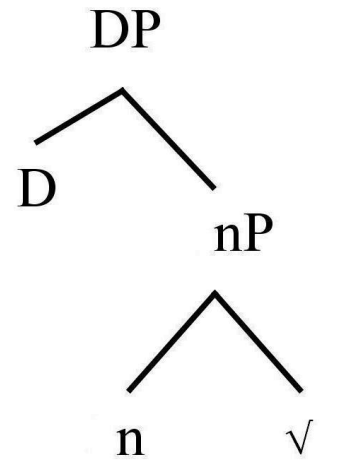

CV

t frux

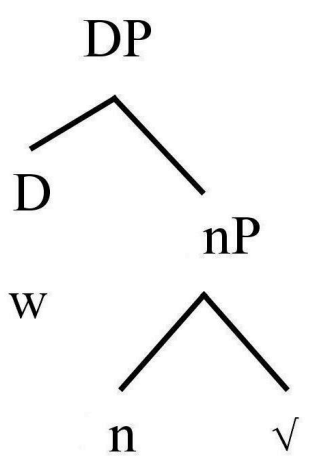

CV

$\varnothing \quad$ frux

The nP headed by $n$ provides one CV unit which accommodates the feminine $t$ - in (20a). When raised to $\mathrm{D}$, this $\mathrm{CV}$ has no $\mathrm{C}$ position available for $w$-, thus leading to the form tfruxt. In the masculine form (20b), the CV unit under $n$ remains empty, under the assumption that the masculine has no overt realization in Berber. When raised to $\mathrm{D}$, the empty $\mathrm{CV}$ accommodates $w$-, leading to the form /wfrux/ which surfaces as [ufrux]. The forms tafruxt and afrux are derived in the same manner, as shown in (21a) and (21b).

\footnotetext{
12 There has been an ongoing debate about whether gender heads its own projection (Picallo 1991, Alexiadou 2005, 2007, Haegeman 2000) or pertains to other syntactic heads (Ritter 1993, Lowenstamm 2008). However, there is consensus regarding the fact that gender is located low in the structure, below DP projection.
} 


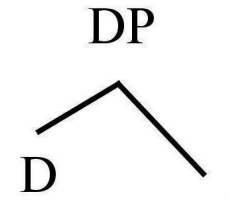

a $\mathrm{nP}$

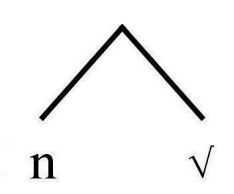

CV

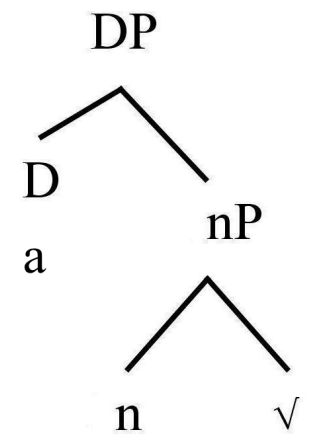

CV

$\mathrm{t} \quad$ frux

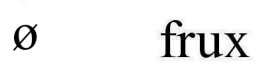

The crucial aspect of this analysis is that $\mathrm{t}$ - is generated below $\mathrm{w}-$. Whether this $\mathrm{t}-$ pertains to $\mathrm{nP}$ or whether it heads its own projection does not affect the analysis, since both possibilities lead to the same result. The reasoning might even hold in analyses that reject the DP hypothesis.

However, one problem arises with the linearization of the above syntactic structures, especially the one in (21a). Within standard analyses in which c-command relations determine the linear order of constituents (Kayne 1994), (21a) should surface as *atfruxt, since a- higher in the structure c-commands t-. Actually, this is true to the extent that it concerns concatenative languages, in which templates play no specific role. Berber, however, makes extensive use of non-concatenative operations, and templates play a central role in arranging the segmental material. Hence, the structures in (21) are meant to reflect the alleged templatic character of Tashlhiyt Berber. Under the assumption that templates determine the linearization of grammatical information, a CV site is inserted under $n$. This CV is intended not only to explain the competition between gender $\mathrm{t}$ - and the $\mathrm{CS} \mathrm{w}$ - but also provides the $\mathrm{V}$ position for the realization of the vowel a-.

Another means to address the problem is to assume that the vowel a- is not a determiner, but rather a nominal marker generated with $\mathrm{t}$ - under $n$, whereas $\mathrm{w}$ - appears under $\mathrm{D}$. The structures in (21) can be restated accordingly as in (22): 


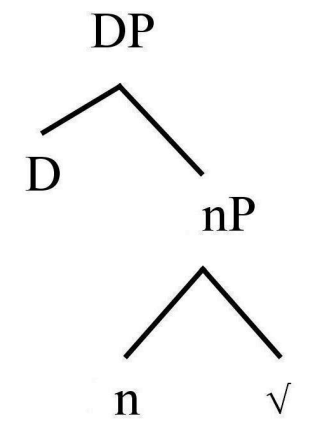

CV

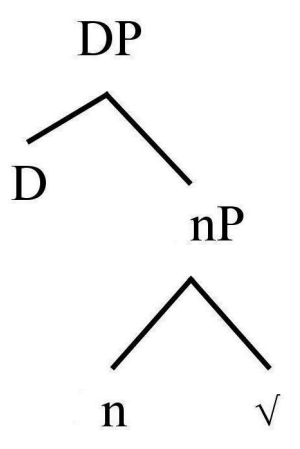

CV
t a frux
a frux

The next section turns to causative imperfective formations. It will be shown that the cooccurrence restrictions the causative and imperfective markers undergo are analysable in the same manner as the CS and gender markers.

\section{The Causative Imperfective}

\subsection{The Geminated Imperfective}

Three processes are involved in the formation of the imperfective in Tashlhiyt Berber, namely a) the gemination of a consonant in the base, b) the prefixation of $t t$-, and c) the insertion of a vowel in the verb. The following examples illustrate these processes:

$$
\text { Aorist Imperfective }
$$

$\begin{array}{lll}\text { a. 'arrive' } & \text { lkm } & \text { lkkm } \\ \text { 'scratch' } & \text { bri } & \text { brri } \\ \text { 'nibble' } & \text { frd } & \text { ffrd } \\ \text { b. 'pull' } & \text { awk } & \text { ttawk } \\ \text { 'carry' } & \text { asi } & \text { ttasi } \\ \text { 'go through hardships' } & \text { rfufn } & \text { ttrfufn } \\ \text { c. 'do' } & \text { skr } & \text { skar } \\ \text { 'collect' } & \text { smun } & \text { smuna } \\ \text { 'connect, paste' } & \text { zdi } & \text { zdaj }\end{array}$

Vowel insertion may operate jointly with prefixation or with gemination to form the imperfective of biconsonantal verbs (e.g. gn $\rightarrow$ ggan 'sleep', matr $\rightarrow$ ttmatar 'oversee'), 
whereas gemination and prefixation never cooccur in the same form, except in a few monoconsonantal verbs such as $k k \rightarrow t t k k a$ 'pass by' and $g \rightarrow t t g g a{ }^{13}$

Gemination occurs in verbs containing no more than three consonants and no full vowels, except in the final position. Two types of verbs are distinguished: verbs geminating the initial consonant, and those geminating the medial consonant. Most accounts of this phenomenon make reference to syllable structure, arguing that the geminating consonant is the one that appears in the onset position (see among others Dell \& Elmedlaoui 1988, 2002, Jebbour 1999, Bensoukas 2001, and MacBride 2004).

Alternatives to syllabic analyses (see Louali \& Philippson 2003, and Lahrouchi 2008) argue that gemination in the imperfective is better analysed as a templatic-based phenomenon resulting in the identification of specific skeletal positions in the sense of McCarthy (1979, 1981), Guerssel \& Lowenstamm (1990), and Lowenstamm (2003). Considered this way, gemination results from consonant spreading into an empty $\mathrm{C}$ position. This is illustrated below with the form $l \mathrm{kkm}$ 'arrive':

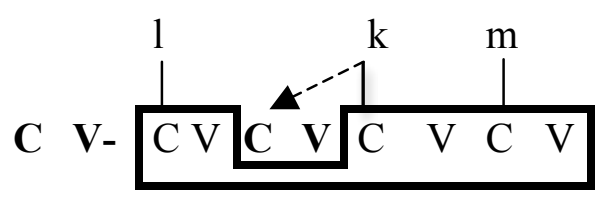

Three observations are in order. First, the initial CV site remains empty. Let us suppose for the moment that in Tashlhiyt Berber, like in Classical Arabic, the initial and medial derivational CV positions (in bold) are never filled at the same time (further details on this issue are provided in section 6.2). Second, the association of segments to the template is not automatic, but rather occurs under grammatical control. That is, the boxed syllables and the medial derivational syllable are filled one after the other by means of two operations, namely root formation and verb derivation. The first operation involves the association of root consonants to the boxed CV positions. Then, verb derivation involves the identification of the medial derivational site by means of consonant spreading, resulting in the gemination of the medial root consonant. However, verbs like frd 'nibble' undergo the same templatic operation as those geminating the medial consonant. The only difference is that they obey a sonority-

\footnotetext{
${ }^{13}$ In Tashlhiyt Berber, the imperfective of monoconsonantal verbs is sometimes given with a non-geminated prefix (see Elmountassir 2003). In other Berber varieties such as Tamashek, the prefix is always non-geminated: e.g. $t$-áz3 'do', t-árcebba 'raise young', $t$-íru 'bray' (Heath 2004).
} 
based constraint, which states that the medial consonant cannot geminate if it the most sonorous segment in the base. ${ }^{14}$

\subsection{The Causative formation}

Causative forms are built by means of a monoconsonantal prefix s- attached to the verbal base. Depending on the properties of the base, the prefix is realized as simplex or geminated. It is argued in Lahrouchi (2003) that an initial templatic site is responsible for the size variation of this prefix. ${ }^{15}$

The phenomenon we will be discussing here relates to the behaviour of the imperfective forms with respect to causativisation. Let us consider the forms in (25):

\begin{tabular}{clllll}
\hline (25) & \multicolumn{2}{c}{ Verb } & \multicolumn{2}{c}{ Causative } \\
& Aorist & Imperfective & Aorist & Imperfective \\
\hline a. 'be damaged' & xsr & xssr & ssxsr & ssxsar & *ssxssr \\
'stand up' & nkr & nkkr & ssnkr & ssnkar & $*_{\text {ssnkkr }}$ \\
'hide' & ntl & nttl & ssntl & ssntal & *ssnttl \\
'lean' & knu & knnu & ssknu & ssknaw & *ssknnu \\
b. 'pick up' & mun & ttmuna & smun & smuna & *ttsmuna \\
'sit down' & gawr & ttgawar & sgawr & sgawar & *ttsgawar \\
'change' & badl & ttbadal & sbadl & sbadal & $*$ ttsbadal \\
'mix up' & xrbq & ttxrbaq & sxrbq & sxrbaq & *ttsxrbaq
\end{tabular}

Verbs in (25a) form their imperfective by means of gemination, while those in (25b) use the prefix tt-. When causativised, the former degeminate their medial consonant and the latter lose the imperfective prefix. Instead, the vowel $a$ appears after the second consonant. The starred forms in the rightmost column are those expected under the assumption that the causative imperfective is derived from the normal imperfective. ${ }^{16}$ Templatic constraints similar to those discussed in the previous section explain the output. In (25b), $t t-$ and $s$ compete for the same position in the template, namely the initial CV site, yielding forms in

\footnotetext{
${ }^{14}$ Apart from Tashlhiyt, all other varieties of Berber invariably geminate the medial consonant in the imperfective, regardless of its sonority. Segments are traditionnally ranked along a scale on the basis of their sonority, which usually explains their organization within the syllable : more sonorous segments stand closer to the peak of the syllable than less sonorous segments (see Sievers 1881, Jespersen 1904, and Clements 1990, amond others). Several works further establish that sonorant geminates are cross-linguistically disfavoured (see for instance Taylor 1985, Podesva 2002, and Kawahara 2007).

${ }_{15}$ Alternatives to the templatic analysis make reference to syllabic and prosodic arguments (see among others Boukous 1987, Lasri 1991, Jebbour 1996, 1999, and Dell \& Elmedlaoui 2002).

${ }^{16}$ One of the reviewers rightly suggests that the causative imperfective may be derived from the cauasative aorist. Under this view, there is no degemination or loss of the prefixal tt- in the causative imperfective, since these don't appear in the causative aorist.
} 
which only the causative prefix is realized. In (25a), the prefixation of $s$ - and the gemination of the medial consonant lead to an undesirable multi-headed structure, where two head positions, namely the initial and the medial derivational $\mathrm{CVs}$, are identified at the same time. The pairs $n k k r / s s n k r$ represented in (26) illustrate the incompatibility of imperfective gemination with the causative prefix:

a.

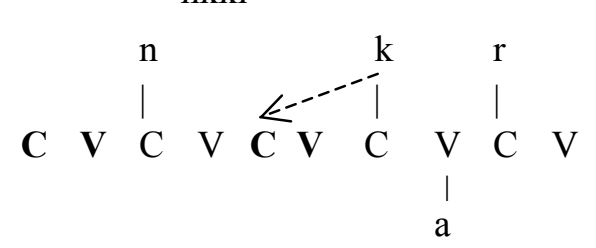

$b$.

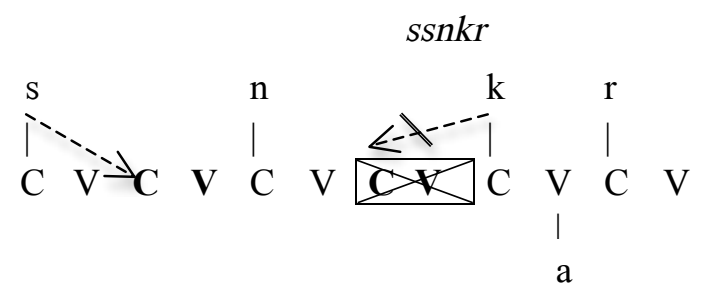

As shown in (26a), the medial consonant geminates through spreading into the medial derivational $\mathrm{CV}$. The same $\mathrm{CV}$, crossed in (26b), exemplifies the case where medial consonant gemination is blocked, since the initial $\mathrm{CV}$ is already activated by the causative prefix. The gemination of both consonants would lead to the identification of both initial and internal derivational heads at the same time. (26b) further shows that the causative prefix enters the derivation with its own skeletal position (the leftmost CV). Then it geminates through spreading rightwards into the first derivational (bolded) CV. Whether the causative prefix geminates or remains simple depends on its ability to spread or to move into the derivational $\mathrm{CV}$ : spreading or movement occurs under specific phonotactic conditions, mainly related to the phonological licensing of the derivational $\mathrm{CV} .{ }^{17}$

The incompatibility of the imperfective prefix tt- with the causative s- is illustrated with the pair ttbadal / sbadal below in (27):
a. ttbadal
b. sbadal

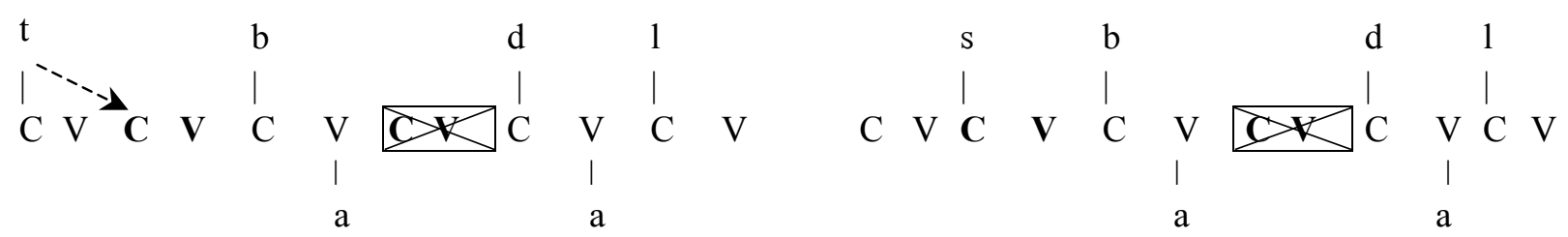

(27a) represents the form $t$ tbadal, where the imperfective prefix geminates through spreading into the first derivational CV. The situation in (27b) resembles the discussion about gender $\mathrm{t}-$ and CS w- in section 5: the causative s- and the imperfective tt- compete for the same position

\footnotetext{
${ }^{17}$ Briefly stated, the first derivational $\mathrm{CV}$ is phonologically licensed when properly governed by the following vowel, which occurs no farther than after the first consonant of the root (on proper government, see section 1.2). In this case, the causative prefix moves into the derivational $\mathrm{CV}$. In the case the derivational $\mathrm{CV}$ is unlicensed, because no adjacent vowel can govern it, the causative prefix spreads. The reader is referred to Lahrouchi (2003) for details about the governing relations and their role in the realization of the causative prefix in Tashlhiyt Berber.
} 
in the template. The reason why s- takes precedence over tt- might reside in the syntactic structure of the verbal phrase: as generally assumed, causativisation is an operation on argument structure; hence the prefix s- should be generated lower in the structure than the Aspect marker tt-. The form in (28) illustrates the proposal:

(28) *ttsbadal / sbadal

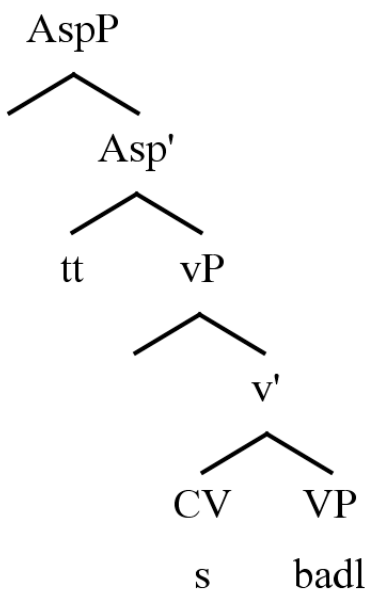

The vP provides an empty CV unit which accommodates the causative s-, while the verbal base $\mathrm{badl}$ generated under VP associates to its own lexical template CVCVCV. Recall from the above section that the causative prefix is assumed to move from its own lexical CV to the derivational $\mathrm{CV}$ that is phonologically unlicensed, thus leading to the simplex variant of the prefix.

Merged together, s- and badl derive the causative form sbadl 'change'. When raised to Asp', the derivational $\mathrm{CV}$ site already hosting s- no longer contains a $\mathrm{C}$ position available for imperfective tt-, thus leading to the form sbadal.

\subsection{One or two derivational CVs?}

The same reasoning as in (28) may hold for the form in (26b). That is, the ungrammaticality of the form *ssnkkr can follow from the fact that the causative prefix and imperfective gemination compete for the same CV site. Since the causative prefix is generated lower in the structure than the imperfective, the medial consonant no longer has a $\mathrm{C}$ position for gemination. The structure in (29) illustrates the derivation: 
(29) *ssnkar

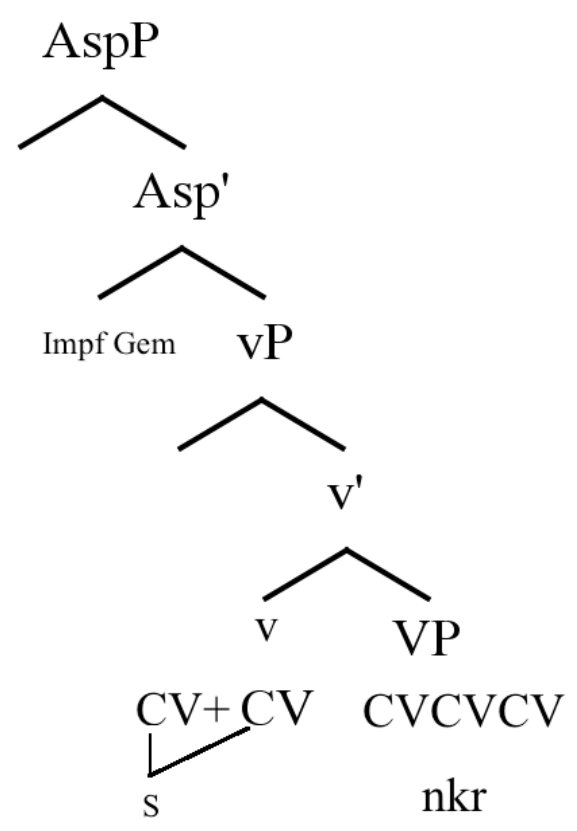

As can be seen from the above structure, the verb $n k r$ 'stand up' is generated along with its template under VP, while the causative prefix ss- appears under v. When merged together, the resulting form is ssnkr 'make stand up, wake up'. Notice that the causative prefix has its own lexical $\mathrm{CV}$, and then geminates through spreading into the $\mathrm{C}$ position of the initial derivational CV under v. When raised to Asp', the derivational CV no longer contains a $\mathrm{C}$ position available for imperfective gemination, thus ruling out the form *ssnkkr.

If the above hypothesis is true then the structure of the template assumed in (24) should be revised. There is indeed no need to posit the existence of two derivational CVs in the templates used in Tashlhiyt Berber. One derivational $\mathrm{CV}$, generated under $\mathrm{vP}$ in the case under discussion, or under $\mathrm{nP}$ in the case of gender and CS formations (section 5), is enough to explain the cooccurrence restrictions at issue. Once this $\mathrm{CV}$ is identified by the causative prefix, there remains no more consonantal position for imperfective gemination or ttprefixation. The whole template should, therefore, consist of one derivational $\mathrm{CV}$ plus the $\mathrm{CV}$ units necessary to accommodate the root material.

The proposal can even be extended to the Classical Arabic verb derivation. The agrammaticality of the form *nkassara 'it shuttered', mentioned previously in section 1.1, can be explained in terms of morphosyntactic competition, rather than prohibited doubleheadedness: the reflexive prefix $n$ - and the medial gemination can be argued to compete for the same CV position. However, while the CV position in Tashlhiyt Berber appears under vP, in Classical Arabic it is generated lower in the structure under VP, in the same position where reflexive n- is added. As to medial gemination, generally use to denote cause or intensity (e.g. 
kattaba 'he made write', farraba 'he made drink', and kassara 'he shuttered'), it is assumed to occur higher in the structure, under vP. ${ }^{18}$ The structure depicted below under (30) illustrates the proposal:

(30) nkasara 'it broke' / *nkassara 'it shuttered'

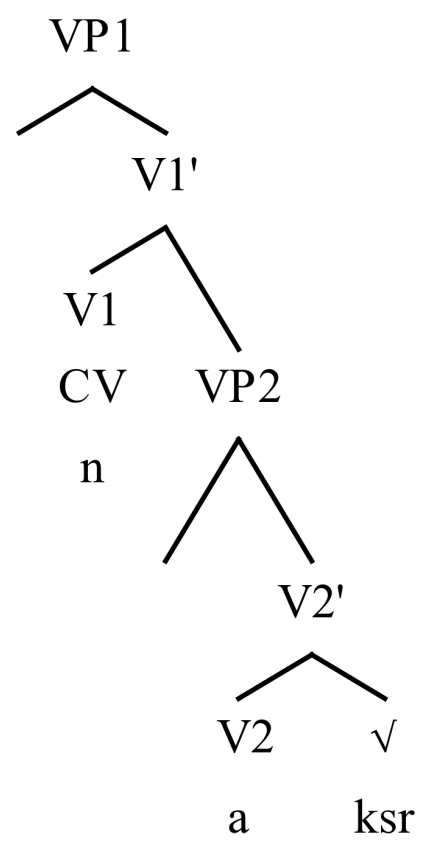

As can be seen from this structure, two VP projections, namely VP2 and VP1, are used to derive the form nkasara 'it broke'. ${ }^{19}$ This is a way of saying that reflexive nkasara is not derived from the consonantal root $k s r$, but directly from the basic verb kasara 'he broke', which in turn derives from the root ksr. Under the common assumption that the head can merge with its complement, the vowel melody under V2 and the root ksr lead to the basic verb kasara 'he broke'. Adding the reflexive prefix n- and the derivational CV under VP1 derives the form nkasara 'it broke'. When raised to $\mathrm{vP}$, the derivational $\mathrm{CV}$ no longer contains a $\mathrm{C}$ position available for geminating the medial consonant $/ \mathrm{s} /$, therefore ruling out the form *nkassara.

\footnotetext{
${ }^{18}$ The vP projection has been originally designed to form causatives (see Chomsky 1995, and Kratzer 1996). In Classical Arabic, argument structure supports the view that reflexives are generated lower in the structure than causatives. Indeed, reflexive verbs such as nkasar 'it broke' require only one argument, while causativisation typically consists in adding an argument to the verb (compare for instance the verb Salima 'he knows' which has one argument to Sallama 'he taught someone' which has two arguments). The reader is referred to Arbaoui (2010: 95) for a justification of the use of little $v$ in Classical Arabic.

${ }^{19}$ The idea that VP can contain two VP projections, one of which selects the other, is not new. It has been proposed in the case of serial verbs found in certain Africain and Asiatic languages (see Larson 1991, and Paul 2004). Well before, Chomsky (1955), and Larson (1988) analysed causative constructions by means of two VP projections. The reader is referred to Arbaoui (2010: 206) for a justification of the use of two VPs in Classical Arabic form III sa:baqa 'he raced'.
} 
In the absence of reflexive $\mathrm{n}$-, the derivational CV under VP1 moves to $\mathrm{vP}$ and then involves gemination of medial consonant, leading to the form kassara 'he shuttered'.

\section{Conclusion}

In this article, it has been argued that the cooccurrence restrictions of certain nominal and verbal markers in Tashlhiyt Berber follow from specific templatic constraints, handled in syntactic structures. So-called construct state w- and gender t- have been shown to compete for the same templatic position. Within the standard DP projection, it has been proposed that an empty $\mathrm{CV}$ site hosts gender $\mathrm{t}$ - under $\mathrm{nP}$. When raised to $\mathrm{D}$, there is no longer a $\mathrm{C}$ position available for the association of w-, yielding forms where only the feminine marker is realized. The same reasoning holds in imperfective forms. The association of the causative prefix to the empty CV site under the vP explains the absence of imperfective gemination and ttprefixation, generated higher in the structure under Aspect. Extended to the case of Classical Arabic verb conjugation, the competition hypothesis allows explaining why reflexive n- never co-occurs with medial consonant gemination: though semantically viable nkassara 'it shuttered' in ruled out because reflexive n- generated under lower in the structure than intensive gemination fills the only $\mathrm{C}$ position provided by the derivational $\mathrm{CV}$.

These analyses ultimately have implications for the way syntax, morphology and phonology interact: templates are indeed argued to mediate the interaction between these components of Grammar. Handled in syntactic structure, templates allow unifying standard phonological, morphological and syntactic accounts of the co-occurrence restrictions examined in Tashlhiyt Berber. They are also assumed to project syntactic nodes, in contradistinction with familiar syntactic models in which only features are handled in syntactic structures.

\section{References}

Abney, Steven P. 1987. The English Noun Phrase in its Sentential Aspects. Doctoral dissertation, MIT, Cambridge, Massachusetts.

Achab, Karim. 2003. Alternation of State in Berber. In Jacqueline Lecarme (ed.), Research in Afroasiatic Grammar II, pp. 1-20. Amsterdam: John Benjamins.

Alexiadou, Artemis, Liliane Heageman \& Melita Stavrou. 2007. Noun Phrase in the Generative Perspective. Berlin - New York: Mouton de Gruyter.

Arbaoui, Nor elhouda. 2010. Les dix formes de l'arabe classique à l'interface syntaxe/phonologie. PhD dissertation, University Paris 7. 
Bader, Yousef \& Michael Kenstowicz. 1987. Syllables and Case in Kabyle Berber. Lingua 73: 279-299.

Bendjaballah, Sabrina. 1999. Trois figures de la structure interne des gabarits: activité morphologique du niveau squelettal des représentations phonologiques en berbère, somali et bedja. Paris: Université Paris 7, doctoral dissertation.

Bendjaballah, Sabrina. 2001. The «Negative Preterit» in Kabyle Berber. Folia Linguistica XXXIV/3-4: 185-220.

Bendjaballah, Sabrina \& Martin Haiden. 2008. A Typology of Emptiness in Templates. In Jutta M. Hartmann, Veronika Hegedüs \& Henk van Riemsdijk (eds.), Sounds of Silence: Empty Elements in Syntax and Phonology, pp. 2-59. Oxford, Amsterdam: Elsevier.

Bensoukas, Karim. 2001. Stem Forms in the Nontemplatic Morphology of Berber. Mohamed 5 University, Doctorat d'Etat Thesis.

Bernstein, Judy. 1993. Topics in the Syntax of Nominal Structure across Romance. Doctoral dissertation, CUNY.

Boukous, Ahmed. 1987. Phonotactique et domaines prosodiques en berbère. Université Paris 8: thèse de doctorat d'Etat.

Chaker, Salem. 1992. Une décennie d'études berbères (1980-1990). Bibliographie critique: langue, littérature, identité. Algiers: Bouchène.

Chomsky, Noam. 1955. The logical structure of linguistic theory Chicago, Illinois: University of Chicago Press.

Chomsky, Noam. 1995. The Minimalist Program. MIT Press.

Chierchia, Gennaro. 1998. Plurality of mass nouns and the notion of semantic parameter. In S. Rothstein (Ed.), Events and Grammar, pp. 53-103. Netherlands, Dordrecht: Kluwer.

Clements, George N. 1990. The role of the sonority cycle in core syllabification. In Kingston and Beckman (Eds), Papers in Laboratory Phonology 1: Between the grammar and physics of speech, pp. 283-333. New York: CUP.

Chomsky, Noam. 1986. Barriers. Cambridge, Massachusetts: MIT.

Dell, François \& Mohamed Elmedlaoui. 1988. Syllabic Consonants in Berber: Some New Evidence. Journal of African Languages and Linguistics 10: 1-17.

Dell, François \& Mohamed Elmedlaoui. 2002. Syllables in Tashlhiyt Berber and in Moroccan Arabic. The Netherlands: Kluwer Academic Publishers.

Dell, François \& Abdelkrim Jebbour. 1991. Phonotactique des noms à voyelle initiale en berbère (chleuh de Tiznit, Maroc). Linguistic Analysis 21: 119-147. 
El Moujahid, El Houssaïn. 1997. Grammaire générative du berbère, morphologie et syntaxe du nom en tachelhit. Rabat: publications de la faculté des lettres et des sciences humaines.

El Mountassir, Abdallah. 2003. Dictionnaire des verbes tachelhit-français (parler berbère du sud du Maroc). Paris: L'Harmattan.

Ennaji, Moha. 2001. The Construct State in Berber. Studies in the Linguistic Sciences 31/2: $55-72$.

Grammont, Maurice. Traité de phonétique. Paris: Delagrave.

Guerssel, Mohand. 1986. Glides in Berber and syllabicity Linguistic Inquiry 17/1: \&-12.

Guerssel, Mohand. 1987. The status of lexical category preposition in Berber: implication for the nature of construct state. In M. Guerssel \& K. Hale (eds.), Studies in Berber Syntax. MIT, Lexicon Project Working Papers.

Guerssel, Mohand. 1992. On the Case System of Berber. Canadian Journal of Linguistics 37/2: 175-195.

Guerssel, Mohand. 1995. Berber Clitic Doubling and Syntactic Extraction. Revue québécoise de linguistique 24/1: 111-133.

Guerssel, Mohamed and Lowenstamm, Jean. 1990. The Derivational Morphology of the Classical Arabic Verbal System. Ms. UQAM \& Université Paris 7.

Heath, Jeffrey. 2004. Grammar of Tamashek (Tuareg of Mali). Ms. University of Michigan.

Idrissi, Ali. 2000. On Berber plurals. In Jacqueline Lecarme, Jean Lowenstamm and Ur Shlonsky (eds.), Research in Afroasiatic Grammar, pp. 101-124. Amsterdam: John Benjamins.

Jebbour, Abdelkrim. 1996. Morphologie et contraintes prosodiques en berbère (tachelhit de Tiznit) : analyse linguistique et traitement automatique. Rabat: Université Mohamed V, Doctorat d'Etat Thesis.

Jebbour, Abdelkrim. 1999. Syllable weight and syllable nuclei in Tashlhiyt Berber of Tiznit. Cahiers de Grammaire 24: 95-116.

Jespersen, Otto. 1904, Lehrbuch der Phonetik. Leipzig and Berlin: B. G. Teubner.

Kaye, Jonathan \& Jean Lowenstamm. 1984. De la syllabicité. In François Dell, Daniel Hirst \& Jean-Roger Vergnaud (eds.), Forme sonore $d u$ langage, pp. 123-159. Paris: Hermann.

Kratzer, AngeliKa. 1996. Severing the external argument from its verb, in J. Rooryck \& L. Zaring (eds.) Phrase Structure and the lexicon, pp.109-137. Dordrecht: Kluwer Academic Publishers. 
Lahrouchi, Mohamed. 2003. Manifestations gabaritiques dans la morphologie verbale du berbère (parler chleuh d'Agadir). Recherches Linguistiques de Vincennes 32: 61-82.

Lahrouchi, Mohamed. 2008. A Templatic Approach to Gemination in the Imperfective Stem of Tashlhiyt Berber. Studies in African Linguistics 37/1: 21-60.

Lahrouchi, Mohamed \& Philippe Ségéral. 2009. Morphologie gabaritique et apophonie dans un langage secret féminin (taqjmit) en berbère tachelhit. Revue Canadienne de Linguistique 54/2: 291-316.

Lahrouchi, Mohamed \& Philippe Ségéral. 2010. Peripheral vowels in Tashlhiyt Berber are phonologically long: Evidence from Tagnawt, a secret language used by women. Brill's Annual of Afroasiatic Languages and Linguistics 2: 202-212.

Lasri, Ahmed. 1991. Aspects de la phonologie non-linéaire du parler berbère (chleuh de Tidli). Université de Paris 3 : thèse de doctorat.

Larson, Richard. 1988. On the double object construction. Linguistic Inquiry 19: 335- 391.

Larson, Richard. 1991. Some issues in verb serialization. In C. Lefebvre (ed.), Verb Serialization, pp. 185 - 210. Amsterdam: Benjamins.

Louali, Naïma and Philippson, Gérard. 2003. Le thème de l'aoriste intensif : formes multiples, contenu unique. Collection d'articles $2^{\text {ème }}$ Bayreuth Frankfurter Kolloquium zur Berberologie, pp. 79-94. Berber Studies, Rüdiger Köppe Verlag.

Lowenstamm, Jean. 1991. Vocalic Length and Centralization in Two Branches of Semitic (Ethiopic and Arabic). In Alan S. Kaye (Ed.), Semitic Studies in honor of Wolf Leslau on the occasion of his eighty-fifth birthday, pp. 949-965. Wiesbaden: Otto Harrassowitz.

Lowenstamm, Jean. 1996. CV as the only syllable type. In Jacques Durand \& Bernard Laks (eds.), Current Trends in Phonology: Models and Methods, Volume 2, pp. 419-441. Salford: European Studies Research Institute, University of Salford.

Lowenstamm, Jean. 1999. The Beginning of the Word. In John Rennison \& Klaus Kühnhammer (eds.), Phonologica, pp. 153-167. The Hague: Holland Academic Graphics.

Lowenstamm, Jean. 2003. A propos des gabarits. Recherches Linguistiques de Vincennes 32: 7-30.

Lowenstamm, Jean. 2008. On Little n, $\sqrt{ }$, and Types of Nouns. In Jutta M. Hartmann, Veronika Hegedüs \& Henk van Riemsdijk (eds.), Sounds of Silence: Empty Elements in Syntax and Phonology, pp. 105-144. Oxford, Amsterdam: Elsevier.

MacBride, Alexander. 2004. A constraint based approach to morphology. UCLA, doctoral dissertation. 
McCarthy, John. 1979. Formal problems in Semitic phonology and morphology. Doctoral dissertation, MIT. Distributed by Indiana University Linguistics Club, New York: Garland Press.

McCarthy, John. 1981. A prosodic Theory of Nonconcatenative Morphology. Linguistic Inquiry 12: 373-418.

Ouhalla, Jamal. 1988. The Syntax of Head Movement: A Study of Berber. Doctoral dissertation London: University College.

Ouhalla, Jamal. 1996. The Construct State in Berber. In Jacqueline Lecarme, Jean Lowenstamm \& Ur Shlonsky (eds.), Studies in Afroasiatic Grammar, pp. 278-301. The Hague: Holland Academic Graphics.

Ouhalla, Jamal. 2005. Agreement features, agreement and antiagreement. Natural Language and Linguistic Theory 23: 655-686.

Rijkhoff, Jan. 2002. The Noun Phrase. Oxford: Oxford University Press.

Ritter, Elizabeth. 1991. Two Functional Categories in Noun Phrases: Evidence from Modern Hebrew. In Susan Rothstein (ed.), Perspectives on Phrase Structure, pp. 37-62. New York: Academic Press.

Ritter, Elizabeth. 1993. Where's Gender?. Linguistic Inquiry 24/4: 795-803.

Scheer, Tobias. 2004. A Lateral Theory of Phonology. Vol. 1: What is CVCV, and why should it be? Studies in Generative Grammar. Berlin: Mouton de Gruyter.

Selkirk, Elisabeth. 1984. On the major class features and syllable theory. In. Aronoff, M. \& Oehrle, R.T. (eds.), Language Sound Structures, pp. 107-136. Cambridge, MA: MIT Press.

Sievers, Eduard. 1881. Grundzüge der Phonetik. Leipzig: Breitkopf and Hartel.

Shlonsky, Ur. 2004. The Form of Semitic Noun Phrases. Lingua 114/15, pp. 1465-1526

Vycichl, Werner. 1957. L'article défini du berbère. Mémorial André Basset, Paris, pp. 139146.

Yip, Moira. 1988. Template Morphology and the Direction of Association. Natural Language and Linguistic Theory 6: 551-577. 